PRAEFATIO

cum inde non pauca subsidia ad codices aestimandos peti posse viderem, statui iis demum editis ad prolegomena illa accedere.

Scrib. Hauniae mense Novembri MDCCCLXXXV

I. L. Heiberg

\title{
ADDITAMENTVM PRAEFATIONIS
}

Euclidem decimum librum Elementorum scripsisse censet scholiasta quidam, ut et de magnitudinibus conmensurabilibus atque incommensurabilibus et de magnitudinibus rationalibus atque irrationalibus doceret. paulo fusius de eadem re loquitur Abu Othman, qui vixit saeculo $\mathrm{X}$ et e fontibus Graecis, videlicet Pappi commentariis, hausisse videtur. utrumque locum in testimonia recepi.

Multi homines docti, inter quos nominandi sunt Simon Stevin, Jean Montucla, G. H. F. Nesselmann, M. G. Zeuthen, Moritz Cantor, Thomas Heath, Paul-Henri Michel, explanare conati sunt, quo consilio Euclides decimum librum conscripserit.

Mea quidem sententia Euclides sibi proposuit, ut demonstraret quae fieret congruentia consensusque, cum in construendo triangulo rectangulo magnitudines irrationales simplicissimae adhiberentur. in propositionibus 10 et 27-35, in quibus magnitudines irrationales simplicissimae construuntur, theoriae fundamenta iaciuntur. in propositionibus 36-41 sex summae irrationales harum magnitudinum efficiuntur:

1. ex duobus nominibus prop. 36

2. ex duobus mediis prima prop. 37

3. ex duobus mediis secunda prop. 38 
4. maior

prop. 39

5. spatio rationali et medio aequalis quadrata prop. 40

6. duobus spatiis mediis aequalis quadrata prop. 41

Tum Euclides trianguli rectanguli auxilio usus (de quo vide definitiones alteras) alteras sex summas irrationales efficit:

1. ex duobus nominibus primam

prop. 48

2. ex duobus nominibus secundam

prop. 49

3. ex duobus nominibus tertiam

prop. 50

4. ex duobus nominibus quartam

prop. 51

5. ex duobus nominibus quintam

prop. 52

6. ex duobus nominibus sextam

prop. 53

Tum primum theoriae caput demonstratur, quod in tabulis I et II reddidi. Euclides cum in propositionibus 36-41 sex summas magnitudinum irrationalium constitucret, in propositionibus 73-78 sex differentias earundem magnitudinum irrationalium efficit. sunt autem hae:

1. apotome

prop. 73

2. prima apotome mediae

prop. 74

3. mediae apotome secunda

prop. 75

4. minor prop. 76

5. recta cum rationali totum medium efficiens prop. 77

6. recta cum medio totum medium efficiens prop. 78

Tum iterum trianguli rectanguli auxilio usus (de quo vide definitiones tertias) alteras sex differentias irrationales efficit:

1. apotome prima

prop. 85

2. apotome secunda prop. 86

3. apotome tertia prop. 87

4. apotome quarta prop. 88

5. apotome quinta prop. 89

6. apotome sexta prop. 90

Tum alterum theoriae caput demonstratur, quod in tabulis III et IV reddidi. 


\section{PRAEFATIO}

Propositionum 112 et 113 ope duodecim triangula rectangula construuntur (cf. tabulam V). quae propositiones cum artissime cum totius libri ratione coniunctae sint, haud dubitandum est quin ipsius Euclidis sint. idem dici potest de propositionibus 114 et 115 .

Quinque tabulis id quod liber decimus Elementorum continet more loquendi mathematico quo nunc uti solemus reddidi. quae quo facilius a mathematicarum artium peritis intelligerentur, sermone usus sum Anglorum, non Latino. ceterum cf. quae scripsi in ephemeride Platon 11, 1959, 371-398.

Scr. Athenis mense Decembri MCMLXIX

E. S. Stamatis 